\title{
Discovery of novel inhibitors of LEDGF/p75-IN protein-protein interactions
}

\author{
Tino Wilson Sanchez ${ }^{\mathrm{a}}$, Bikash Debnath ${ }^{\mathrm{a}}$, Frauke Christ ${ }^{\mathrm{b}}$, Hiroyuki Otake ${ }^{\mathrm{a}}$, Zeger Debyser ${ }^{\mathrm{b}}$, \\ Nouri Neamati ${ }^{\mathrm{a}, *}$ \\ a Department of Pharmacology and Pharmaceutical Sciences, School of Pharmacy, University of Southern California, Los Angeles, CA 90089, USA \\ ${ }^{\mathrm{b}}$ Laboratory for Molecular Virology and Gene Therapy, Division of Molecular Medicine, Katholieke Universiteit Leuven (KULeuven), Kapucijnenvoer 33, B-3000 Leuven, \\ Flanders, Belgium
}

\section{A R T I C L E I N F O}

\section{Article history:}

Received 2 October 2012

Revised 25 November 2012

Accepted 3 December 2012

Available online $\mathrm{xxxx}$

\section{Keywords:}

HIV

Integrase

LEDGF/p75

Antiviral

N-Acylhydrazones

Hydrazines

\begin{abstract}
A B S T R A C T
Human lens epithelium-derived growth factor (LEDGF)/p75 plays an important role in the HIV life cycle by stimulating integrase (IN)-led viral DNA integration into cellular chromosomes. Mechanistic studies show the majority of IN inhibitors chelate magnesium ions in the catalytic active site, a region topologically distant from the LEDGF/p75 binding site. Compounds disrupting the formation of LEDGF/p75 and IN complexes serve as a novel mechanistic approach different from current antiretroviral therapies. We previously built pharmacophore models mimicking LEDGF/p75 residues and identified four classes of LEDGF/p75-IN inhibitors. Substructure and similarity searches yielded additional LEDGF/p75-IN inhibitors containing an acylhydrazone moiety. The most potent of the acylhydrazones inhibited LEDGF/p75-IN interaction with an $\mathrm{IC}_{50}$ value of $400 \mathrm{nM}$. We explored structure-activity relationships (SAR) and identified new acylhydrazones, hydrazines, and diazenes as lead molecules for further optimization. Two lead LEDGF/p75-IN inhibitors showed antiviral activity.
\end{abstract}

(c) 2012 Elsevier Ltd. All rights reserved.

\section{Introduction}

The interaction between transcriptional co-activator LEDGF/p75 and HIV-1 IN is an important target to improve current antiretroviral therapeutic regimens. ${ }^{1}$ The high mutation rate $^{2,3}$ and the pools of drug-resistant viral strains demand the identification of innovative targets to impinge on viral replication. ${ }^{4,5}$ The LEDGF/ p75 host protein directs HIV-1 IN and the pre-integration complex (PIC) to actively transcribe regions for viral DNA integration into the human genome. ${ }^{6,7}$ Mutagenesis studies elucidated that a small number of LEDGF/p75 residues (K364, I365, D366, F406, V408) from the IN binding domain (IBD) and a few IN residues (E69, A129, W132, V165, R166, Q168) are responsible for the LEDGF/ p75-IN interaction. ${ }^{8,9}$ Crystallography structures reveal a homology between the LEDGF/p75 interaction sites of both HIV-1 and HIV-2 IN proteins, thus supporting the essential role of LEDGF/ p75 in viral replication and fitness. ${ }^{10,11}$

Knockdown of cellular LEDGF/p75 expression shows a significant decrease in viral genomic integration, viral fitness, and an increase in LTR circles that is indicative of an inability to incorporate viral DNA into host chromosomes. ${ }^{12,13}$ Knockout cell lines however, reveal HIV replication can partially recover using alternate

\footnotetext{
* Corresponding author. Tel.: +1 323442 2341; fax: +1 3234421390.

E-mail address: neamati@usc.edu (N. Neamati).
}

pathways for viral integration. Hepatoma-derived growth factor related protein (HRP-2) IBD interacts with HIV-1 IN in LEDGF/ p75-depleted cells and is also susceptible to quinoline-based LEDGF/p75-IN inhibitors. ${ }^{14}$

The identification of LEDGF/p75-IN inhibitors is an important step to stay ahead of a still evolving lentivirus. Diketo acids containing an indole have also been explored as LEDGF/p75-IN inhibitors. $^{15,16}$ Occupying the LEDGF/p75 binding site, bi-modal allosteric inhibitors disrupt LEDGF/p75-IN interaction and lock IN into a pre-mature multimeric state. ${ }^{17,18}$ Our previously reported dual antagonists for IN and LEDGF/p75-IN inhibition were initially developed for IN strand transfer (ST) and had a central catechol attached to a carboxamide linker. ${ }^{19}$ More recently, crystal structures of LEDGF/p75-IN inhibitory peptides ${ }^{20}$ and small molecules confirmed the binding mechanism of LEDGF/p75-IN inhibitors to be at the IN dimer interface. ${ }^{21}$

$\mathrm{X}$-ray crystallography structures are an invaluable tool for therapeutic drug design ${ }^{22,23}$ and have validated the interaction between cellular LEDGF/p75 and HIV-1 IN. ${ }^{10,11}$ A crystal structure of the quinolin-3-yl acetic acid bound to the IN core domain, confirmed the inhibitory binding mechanism is located at a pocket close to the IN interface. ${ }^{21}$ Another study reported several crystal structures of LEDGF/p75-IN inhibitors identified through fragment screening; adding to a growing list of templates available for rational drug design. ${ }^{24}$ In a separate study (unpublished), we 


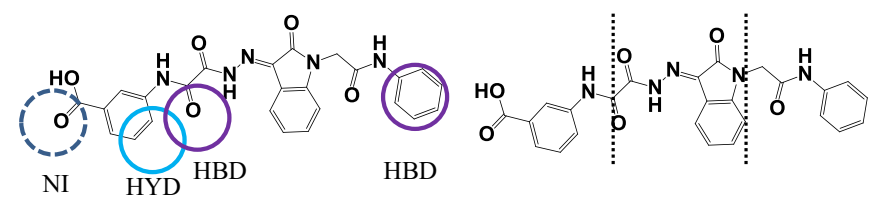

Figure 1. A lead molecule with an N-acylhydrazone was identified from a four feature pharmacophore model mimicking LEDGF/p75 IBD K364, I365, and D366 residues key to viral replication. Representative hydrogen bond donor (HBD) groups in purple, a hydrophobic (HYD) group in teal, and a negative ionizable group in a dashed blue circle is shown. New compounds were explored focusing on a central $\mathrm{N}$-acylhydrazone and two opposite cyclic rings, all components not highlighted as pharmacophore model-related groups.

developed pharmacophore models mimicking LEDGF/p75 IBD residues K364, I365, and D366. The structure of a lead N-acylhydrazone that was identified from the pharmacophore models and inhibited LEDGF/p75-IN interaction in vitro with an $\mathrm{IC}_{50}$ value below $25 \mu \mathrm{M}$ is provided in Figure 1. The pharmacophoric mapping of similar LEDGF/p75-IN inhibitors prompted an investigation into the importance of the central N-acylhydrazone linker. Several lead molecules containing $\mathrm{N}$-acylhydrazones were then subjected to substructure and similarity studies which led to the discovery of new acylhydrazone and hydrazine-based LEDGF/p75-IN inhibitors.

$\mathrm{N}$-Acylhydrazones are known to treat tuberculosis via a mechanism of action targeting the biosynthesis of mycolic acids of the bacteria cell wall. ${ }^{2,26}$ Antibacterial salinizide, aconiazide, and other acylhydrazone prodrugs are hydrolyzed to the active hydrazide component isoniazid (Fig. 2) ${ }^{27,28} \mathrm{~N}$-acylhydrazones have also been identified to have antiretroviral activity by binding to HIV-1 capsid $^{29}$ and reverse transcriptase $e^{30,31}$ suggesting potential antiviral activity for this class of LEDGF/p75-IN inhibitors. In this study we identified acylhydrazones, hydrazines, and diazenes as LEDGF/p75-IN inhibitors, examined their SAR, and explored strategies to evade cellular metabolism.

\section{Results and discussion}

\subsection{SAR for the inhibition of HIV-1 IN and LEDGF/p75 interaction}

\subsubsection{Acylhydrazones}

Developing small molecule inhibitors that target allosteric pockets and alternate stages of the viral life cycle is the next step in a marathon against expanding pools of drug-resistant strains. We identified $\mathrm{N}$-acylhydrazones as a potential new lead compound using LEDGF/p75 IBD-based pharmacophore models. The examination of small molecules with a central acylhydrazone evolved from a series of SAR studies using substructure searches. Further LEDGF/ p75-IN inhibitors were identified from a commercial database (Enamine, Ltd) of half a million compounds and screened using an amplified luminescent proximity homogeneous assay. ${ }^{32}$

Structures of select $\mathrm{N}$-acylhydrazones and related compounds are shown in Figure 3. Compounds $\mathbf{4}$ and $\mathbf{5}$ both inhibited
LEDGF/p75-IN interaction with an $\mathrm{IC}_{50}$ value of $4 \mu \mathrm{M}$ (Table 1 ). Changing the position of the pyridine nitrogen from a meta (5) to an ortho position in compound $\mathbf{6}$ improved activity three-fold with an $\mathrm{IC}_{50}$ of $1.3 \pm 0.3 \mu \mathrm{M}$. A pyrazine-carbohydrazine (7) exhibited the best activity with an $\mathrm{IC}_{50}$ of $0.4 \pm 0.1 \mu \mathrm{M}$ while compound 8 had a pyrazine opposite a dichlorobenzylidene and was inactive at $50 \mu \mathrm{M}$. Unlike LEDGF/p75-IN inhibitors 4-7, compounds 3 and 8 lacked a phenol ring and did not exhibit inhibitory activity at $50 \mu \mathrm{M}$.

LEDGF/p75-IN inhibitors containing a pyrazole followed a similar pattern of activity. Compounds 10-12 without a phenol ring were inactive at $50 \mu \mathrm{M}$ while 13 had an $\mathrm{IC}_{50}$ of $2 \pm 1 \mu \mathrm{M}$, at least a 25-fold improvement. Compounds 9 and 15 both had 2-hydroxyl-naphthalene moieties and similar inhibition profiles. Compound $\mathbf{1 6}$ had a pyrazole instead of a bicyclic ring and also yielded similar activity with an $\mathrm{IC}_{50}$ of $7 \pm 3 \mu \mathrm{M}$.

The presence of a phenol in compounds 1-16 seems to have improved LEDGF/p75-IN inhibition. Other examples of hydroxybenzylidene acylhydrazones will need to be tested to confirm this conclusion. Prodrug strategies have previously been explored to evade the cellular metabolism associated with acylhydrazones. ${ }^{33}$ In our assays, the anti-tuberculosis drug, isoniazid, did not inhibit the LEDGF/p75-IN interaction at $1000 \mu \mathrm{M}$ (data not shown). Interestingly, 4,6-bis(ethylamino)-1,3,5-triazine-2-carbohydrazide (19) had an $\mathrm{IC}_{50}$ value of $6 \pm 2$. Substituting the terminal hydrazide with a carboxamide linker (20) reduced activity more than threefold. Replacing the pyrazole of $\mathbf{1 6}$ with a thiofuran (21) did not maintain inhibitory activity, while compound $\mathbf{2 2}$ with a hydroxythiophene showed a weak potency. Compounds 26 and $\mathbf{2 7}$ had an $\mathrm{IC}_{50}$ of $8 \pm 3$ and $13 \pm 5 \mu \mathrm{M}$, respectively.

It is plausible that the hydroxyl group in some of the 2-phenolbased inhibitors are important for LEDGF/p75-IN inhibitory activity. Many of the inactive analogues replace the hydroxyl group with a methoxyl group or a chlorine while most of the isoniazidlike compounds (e.g., 17 and 18) tested also do not have a 2-phenol. As docking studies reveal in Section 2.2, it is likely the hydroxyl group in the 2 position forms an important hydrogen bond with the target IN dimer interface, thus disrupting the LEDGF/p75-IN complex.

LEDGF/p75-IN inhibitors were also tested against HIV-1 IN catalytic activities in vitro (Table 1 ). Compound $\mathbf{7}$ did not inhibit IN at $100 \mu \mathrm{M}$ while the LEDGF/p75-IN inhibitor 6 exhibited dual activity with a catalytic inhibitory profile for $3^{\prime}$ processing and strand transfer $\mathrm{IC}_{50}$ values of $17 \pm 5$ and $13 \pm 3 \mu \mathrm{M}$, respectively. The remaining LEDGF/p75-IN inhibitors containing pyridines or pyrazines were all inactive at $100 \mu \mathrm{M}$ against IN catalytic activities in vitro. The bromine-substituted compound 14 was the only other acylhydrazone to inhibit strand transfer with an $\mathrm{IC}_{50}$ value of $15 \mu \mathrm{M}$. HIV-1 IN catalytic inhibition by LEDGF/p75-IN inhibitors has been previously identified to induce multimer formation and lock IN into an inactive state. ${ }^{17}$

It has also been suggested that many of the reported dual 2(quinolin-3-yl) acetic acid LEDGF/p75-IN inhibitors act to prevent IN assembly on the viral DNA prior to the integration step. ${ }^{34}$ Since

Anti-tuberculotic acylhydrazone drugs

Salin azid

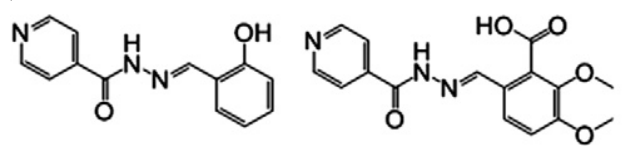

Aconiazide

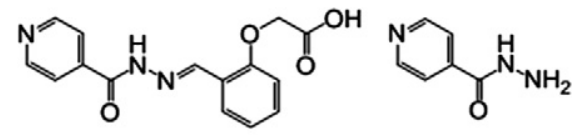

Figure 2. Clinical acylhydrazone-containing drugs have widely been used for tuberculosis. 


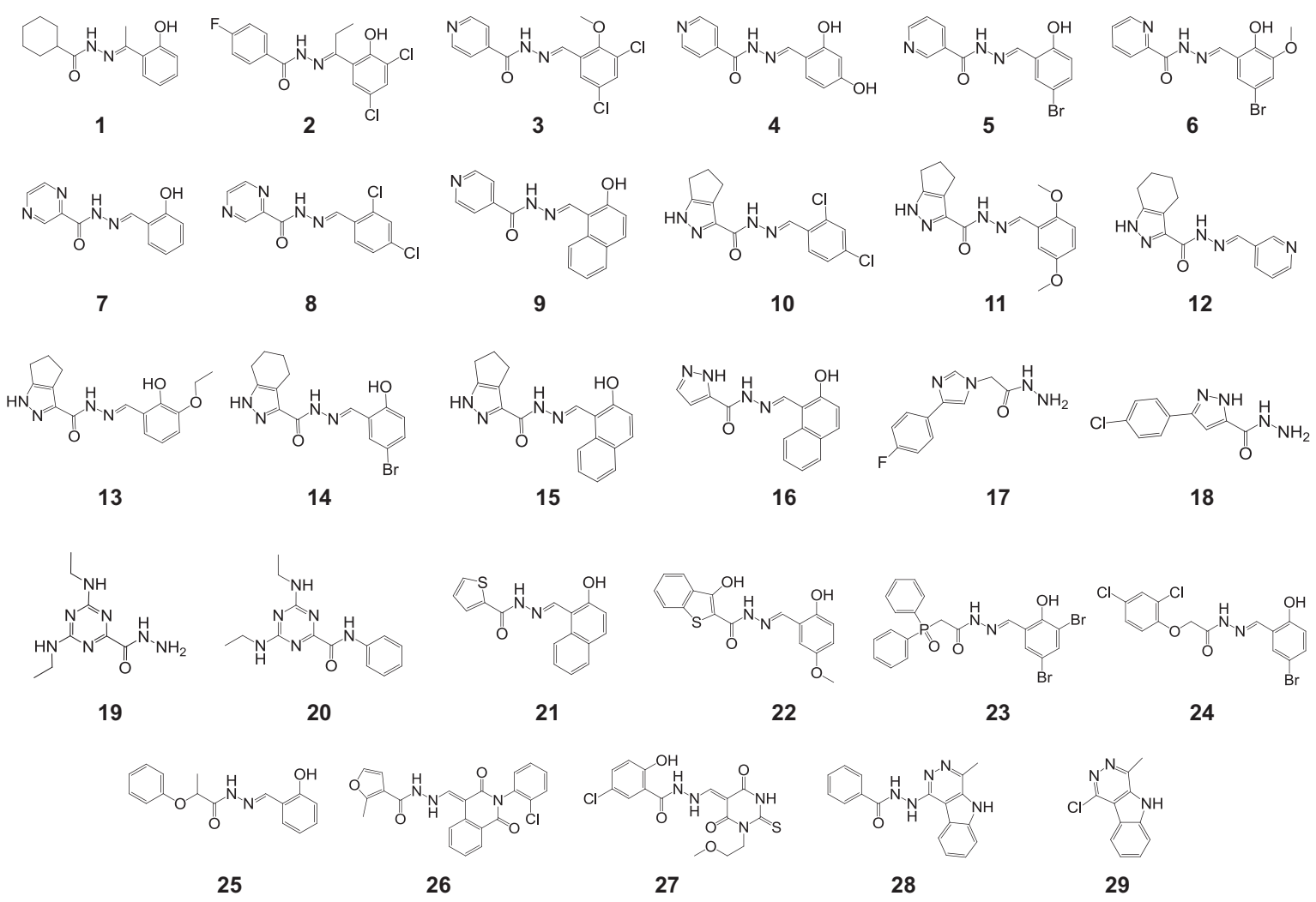

Figure 3. Structures of select N-acylhydrazone-based derivatives and related compounds as potential LEDGF/p75-IN inhibitors.

many of the acylhydrazones reported here do not possess this dual catalytic and cofactor inhibition, we suggest that these compounds are unique LEDGF/p75-IN inhibitors acting to solely disrupt the LEDGF/p75-IN complex formation. Several N-acylhydrazones were chosen for antiviral screening in HIV-infected MT-4 cells. All compounds that had a central $\mathrm{N}$-acylhydrazone provided in this study were ineffective at inhibiting viral infection.

Elevated cellular LEDGF/p75 expression levels have also been observed in a panel of cancers and its role described as a stress-related transcriptional chaperone recruiting anti-apoptotic and prosurvival factors. $^{35,36}$ Although the highly active LEDGF/p75-IN inhibitor 7 did not exhibit cytotoxicity, several other N-acylhydrazones showed significant cytotoxicity in human colon cancer HCT116 p53 +/+ and $-/-$ cell lines (Table S1). The evaluation of cytotoxic LEDGF/p75-IN inhibitors offers the potential that these anticancer compounds may also inhibit LEDGF/p75-related transcriptional activation of oncogenes.

\subsubsection{Hydrazines, diazenes, and related compounds}

In addition to compounds containing a central acylhydrazone linker, we tested additional hydrazines in our AlphaScreen assay to assess the importance of the central carbonyl group (Fig. 4). After identifying several hydrazine 'hits' we aimed to explore the affects of the two central nitrogen atoms by altering the position of the double bond, effectively yielding diazene-based LEDGF/ p75-IN inhibitors. In this series, at least six hydrazine and diazene-based compounds inhibited LEDGF/p75-IN interaction with $\mathrm{IC}_{50}<10 \mu \mathrm{M}$ in vitro (Table 2 ).

LEDGF/p75-IN inhibitor 4-(2-(1-(2-bromophenyl)ethylidene)hydrazinyl)-N-(2-methoxyphenyl)-3-nitrobenzenesulfonamide (35) inhibited the protein-protein interaction with an $\mathrm{IC}_{50}$ of
Table 1

N-Acylhydrazone-based LEDGF/p75-IN inhibitors and analogues

\begin{tabular}{|c|c|c|c|c|}
\hline Compounds & $\begin{array}{l}\text { LEDGF/p75-IN IC } 50 \\
(\mu \mathrm{M})\end{array}$ & $\begin{array}{l}3^{\prime} \text { Proc. } \mathrm{IC}_{50} \\
(\mu \mathrm{M})\end{array}$ & $\begin{array}{l}\text { ST IC }_{50} \\
(\mu \mathrm{M})\end{array}$ & Antiviral $^{\mathrm{a}}$ \\
\hline 1 & $93 \pm 14$ & - & - & $>20$ \\
\hline 2 & $>50$ & - & - & - \\
\hline 3 & $>50$ & $>100$ & $>100$ & - \\
\hline 4 & $4 \pm 2$ & $>100$ & $>100$ & - \\
\hline 5 & $4 \pm 1$ & $>100$ & $>100$ & $>3$ \\
\hline 6 & $1.3 \pm 0.3$ & $17 \pm 5$ & $13 \pm 3$ & $>22$ \\
\hline 7 & $0.4 \pm 0.1$ & $>100$ & $>100$ & $>40$ \\
\hline 8 & $>50$ & $>100$ & $>100$ & - \\
\hline 9 & $6 \pm 3$ & $>100$ & $>100$ & - \\
\hline 10 & $>50$ & - & - & - \\
\hline 11 & $>50$ & $>100$ & $>100$ & $>40$ \\
\hline 12 & $>50$ & - & - & $>20$ \\
\hline 13 & $2 \pm 1$ & $>100$ & $>100$ & $>4$ \\
\hline 14 & $4 \pm 1$ & $29 \pm 12$ & $15 \pm 3$ & - \\
\hline 15 & $4 \pm 2$ & $>100$ & $>100$ & $>17$ \\
\hline 16 & $7 \pm 3$ & $>100$ & $>100$ & $>14$ \\
\hline 17 & $>50$ & - & - & - \\
\hline 18 & $>50$ & - & - & - \\
\hline 19 & $6 \pm 2$ & $<100$ & $<100$ & $>20$ \\
\hline 20 & $21 \pm 2$ & - & - & - \\
\hline 21 & $>50$ & - & - & - \\
\hline 22 & $38 \pm 6$ & $>100$ & $>100$ & - \\
\hline 23 & 50 & 100 & 100 & - \\
\hline 24 & 50 & $>100$ & $>100$ & - \\
\hline 25 & 50 & - & - & - \\
\hline 26 & $8 \pm 3$ & $90 \pm 14$ & $75 \pm 35$ & - \\
\hline 27 & $13 \pm 5$ & 90 & 80 & $>40$ \\
\hline 28 & $>50$ & - & - & - \\
\hline 29 & $>50$ & - & - & - \\
\hline 30 & $5 \pm 0.2$ & $>100$ & $>100$ & $>50$ \\
\hline
\end{tabular}

a Compounds were screened in virally infected MT-4 cells to determine EC $_{50}$ $(\mu \mathrm{M})$. 

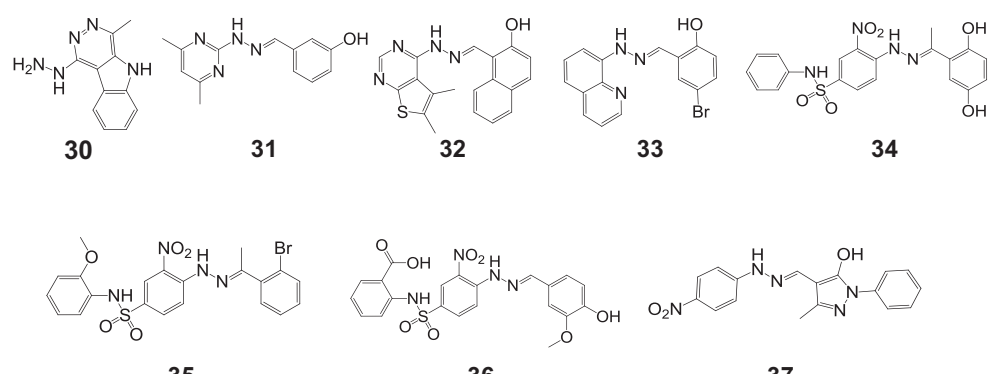

35

36

37

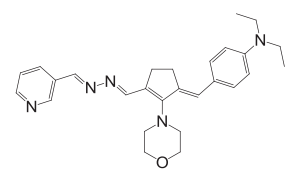

38



39

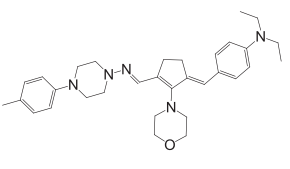

40



41

42

43

44

Figure 4. Structures of select hydrazines, diazenes, and related compounds as potential LEDGF/p75-IN inhibitors.

Table 2

LEDGF/p75-IN inhibitors-hydrazines, diazenes, and related compounds

\begin{tabular}{lllll}
\hline Compounds & $\begin{array}{l}\text { LEDGF/p75-IN } \\
\mathrm{IC}_{50}(\mu \mathrm{M})\end{array}$ & $\begin{array}{l}3^{\prime} \text { Proc. IC } \\
(\mu \mathrm{M})\end{array}$ & $\begin{array}{l}\mathrm{ST} \mathrm{IC}_{50} \\
(\mu \mathrm{M})\end{array}$ & Antiviral $^{\mathrm{a}}$ \\
\hline $\mathbf{3 1}$ & $>50$ & - & - & - \\
$\mathbf{3 2}$ & $6 \pm 1$ & $77 \pm 12$ & $52 \pm 3$ & - \\
$\mathbf{3 3}$ & $>50$ & $>100$ & $>100$ & - \\
$\mathbf{3 4}$ & $13 \pm 3$ & $>100$ & $>100$ & $>28$ \\
$\mathbf{3 5}$ & $6 \pm 4$ & $>100$ & $>100$ & 12 \\
$\mathbf{3 6}$ & $25 \pm 12$ & $>100$ & $>100$ & $>10$ \\
$\mathbf{3 7}$ & $6 \pm 3$ & - & - & - \\
$\mathbf{3 8}$ & $3 \pm 2$ & $>100$ & $>100$ & $>20$ \\
$\mathbf{3 9}$ & $40 \pm 12$ & - & - & - \\
$\mathbf{4 0}$ & $46 \pm 8$ & - & - & - \\
$\mathbf{4 1}$ & $20 \pm 8$ & $>100$ & $>100$ & $>5$ \\
$\mathbf{4 2}$ & $2 \pm 1$ & $>100$ & $>100$ & $>100$ \\
$\mathbf{4 3}$ & $12 \pm 2$ & $>100$ & $>100$ & - \\
$\mathbf{4 4}$ & $36 \pm 9$ & - & - & - \\
\hline
\end{tabular}

$\overline{{ }^{a} \text { Compounds were screened in virally infected MT-4 cells to determine } \mathrm{EC}_{50}}$ $(\mu \mathrm{M})$.

$6 \mu \mathrm{M}$ in vitro and showed antiviral activity in MT-4 cells with an $\mathrm{EC}_{50}$ of $12 \mu \mathrm{M}$. The lack of IN catalytic inhibition suggests either the inhibitor only prevents the LEDGF/p75-IN protein-protein interaction and does not effect multimerization or the antiviral activity relates to another target altogether.

Compound 38 inhibited the LEDGF/p75-IN interaction with an IC $_{50}$ of $3 \mu \mathrm{M}$, a substantial improvement compared to analogues 39 and 40. Hydrazine 41 also had a diazene linker and inhibited the LEDGF/p75-IN interaction with an $\mathrm{IC}_{50}$ of $20 \pm 8 \mu \mathrm{M}$. The identification of this inhibitor led to the screening of more diazenebased compounds and investigating the role of the double bond in between the two central nitrogen atoms. The most active diazene-based LEDGF/p75-IN inhibitor, compound 42, had an $\mathrm{IC}_{50}$ of $2 \pm 1 \mu \mathrm{M}$ but showed no antiviral activity.

We reasoned that cyclization and/or conjugation of the hydrazine or its components into cyclic moieties may improve the metabolic profile and reduce non-specific interactions of this chemical class of LEDGF/p75-IN inhibitors (Fig. 5). In this series, three out of 16 compounds showed $\mathrm{IC}_{50}$ values $<10 \mu \mathrm{M}$ in our AlphaScreen (Table 3). Hydrazine-containing compounds 32 and
54 were the only examples that inhibited both LEDGF/p75-IN interaction and exhibited IN catalytic inhibition in vitro. Compound 56 had a similar structure to 34-36 with a sulfonamide linker and replacing the hydrazine with a piperazine-like ring, and like 35, 4-(4-(4-methoxybenzyl)-1,4-diazepan-1-yl)-3-nitro- $N$ phenylbenzenesulfonamide (56) showed antiviral activity with an $\mathrm{EC}_{50}$ value of $24 \mu \mathrm{M}$. Antiviral LEDGF/p75-IN inhibitors 35 and $\mathbf{5 6}$ had selectivity indexes of $>8$ and $>1$, respectively.

\subsection{Docking and molecular modeling}

Inhibitors from this study were docked in the LEDGF/p75 binding cavity of the IN dimer interface of the 2B4J crystal structure using Generic Optimization Ligand Design (GOLD) software. ${ }^{10,37}$ For comparison of the docking interactions, we merged the cocrystal structure of LEDGF/p75-IN inhibitor (976) imported from $3 \mathrm{LPU}^{21}$ onto $2 \mathrm{~B} 4 \mathrm{~J}$ by superimposing both structures to show the complete IN dimer pocket. Figure 6 shows reported inhibitor 976 can form an $\mathrm{H}$-bond with the main chain nitrogen atoms of E170 and H171 as well as the side chain oxygen atom of T174.

The most active LEDGF/p75-IN inhibitor from the in vitro studies, pyrazine carbohydrazine $\mathbf{7}$, shows it can also form H-bonds with IN residues E170 and H171 while the phenol ring falls in the hydrophobic cavity (Fig. 6). The oxygen atom from the carbonyl of 7 likely forms H-bonds with the main chain amide of E170 and H171 and the pyrazino nitrogen can form H-bond with the T174 side chain. The relative distances of all the interactions observed in the docking studies is less than 3 angstroms which suggests a stacking interaction can also form between the pyrazine and the H171 side chain. It is also possible that a water molecule can form $\mathrm{H}$-bonds with the phenol and the keto groups (not shown). In contrast, the anti-tuberculosis drug isoniazid, did not dock near the A169-T174 region (Fig. S1) and thus does not likely form any interactions capable of disrupting the LEDGF/p75-IN complex as evidenced with an $\mathrm{IC}_{50}$ value $>1000 \mu \mathrm{M}$ in the AlphaScreen assay.

Similar to compound 7, docking studies show antiviral LEDGF/ p75-IN inhibitors 4-(2-(1-(2-bromophenyl)ethylidene)hydrazinyl)-N-(2-methoxyphenyl)-3-nitrobenzenesulfonamide (35) and 


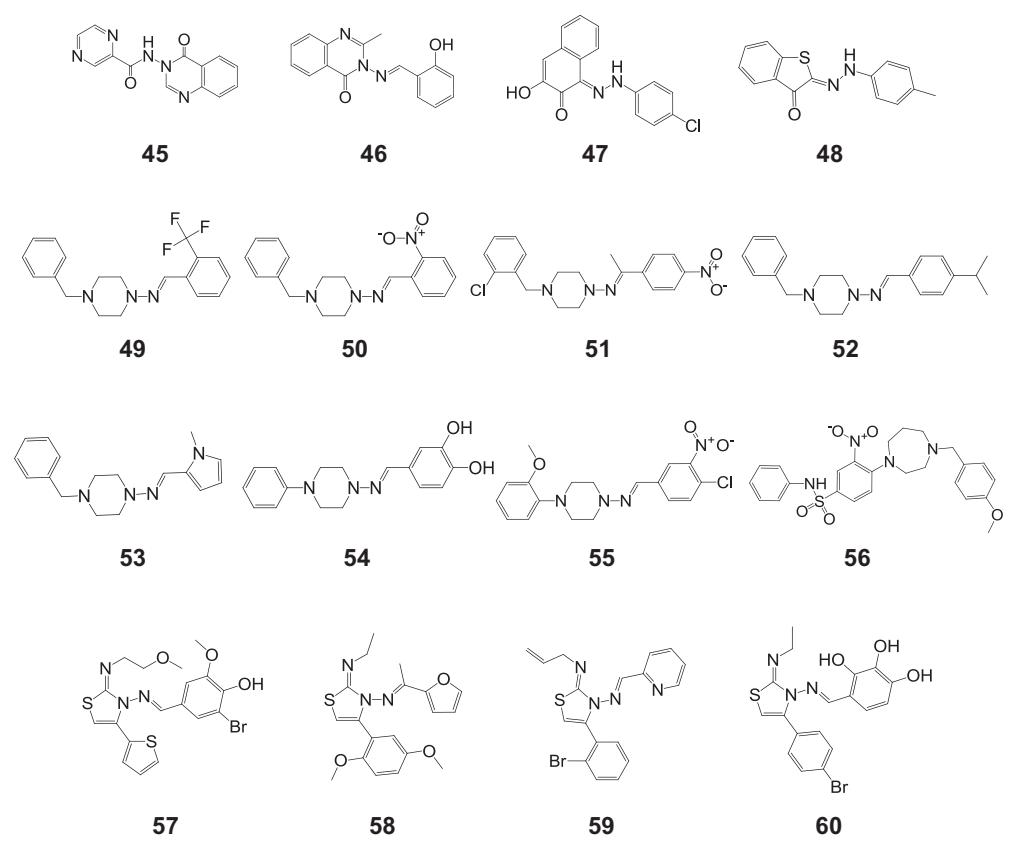

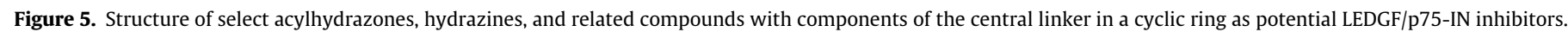

Table 3

LEDGF/p75-IN inhibitors-acylhydrazone and hydrazine moieties in cyclic ring

\begin{tabular}{lllll}
\hline Compounds & $\begin{array}{l}\text { LEDGF/p75-IN IC } \\
(\mu \mathrm{M})\end{array}$ & $\begin{array}{l}3^{\prime} \text { Proc. IC } \\
(\mu \mathrm{M})\end{array}$ & $\begin{array}{l}\mathrm{ST} \mathrm{IC}_{50} \\
(\mu \mathrm{M})\end{array}$ & Antiviral $^{\mathrm{a}}$ \\
\hline $\mathbf{4 5}$ & $39 \pm 6$ & - & - & - \\
$\mathbf{4 6}$ & $>50$ & - & - & - \\
$\mathbf{4 7}$ & $3 \pm 1$ & $>100$ & 100 & $>40$ \\
$\mathbf{4 8}$ & $6 \pm 2$ & $>100$ & $>100$ & $>100$ \\
$\mathbf{4 9}$ & $35 \pm 13$ & $>100$ & $>100$ & - \\
$\mathbf{5 0}$ & $24 \pm 6$ & - & - & - \\
$\mathbf{5 1}$ & $19 \pm 1$ & $>100$ & $>100$ & $>100$ \\
$\mathbf{5 2}$ & 50 & - & - & - \\
$\mathbf{5 3}$ & $32 \pm 7$ & $>100$ & $>100$ & - \\
$\mathbf{5 4}$ & $16 \pm 5$ & $69 \pm 30$ & $31 \pm 19$ & - \\
$\mathbf{5 5}$ & $21 \pm 5$ & $>100$ & $>100$ & $>100$ \\
$\mathbf{5 6}$ & $34 \pm 11$ & - & - & 24 \\
$\mathbf{5 7}$ & $14 \pm 6$ & $>100$ & $>100$ & $>15$ \\
$\mathbf{5 8}$ & $8 \pm 1$ & $>100$ & $>100$ & $>60$ \\
$\mathbf{5 9}$ & $23 \pm 3$ & $>100$ & $>100$ & $>1$ \\
$\mathbf{6 0}$ & $<25$ & - & - & $>35$ \\
\hline
\end{tabular}

a Compounds were screened in virally infected MT-4 cells to determine $\mathrm{EC}_{50}$ $(\mu \mathrm{M})$.

4-(4-(4-methoxybenzyl)-1,4-diazepan-1-yl)-3-nitro- $N$-phenylbenzenesulfonamide (56) can both form H-bonds with E170 and H171 (Fig. 6). The sulphonyl oxygen of these two compounds can form $\mathrm{H}$-bonds between the side chain amine and the main chain amide of H171 while the other sulphonyl oxygen forms an H-bond with T174 side chain hydroxyl group. Selected LEDGF/p75-IN inhibitors 19, 42, and 58 were also docked and showed similar H-bonding patterns within the LEDGF/p75 binding pocket (Fig. S1).

\section{Conclusion}

Small molecules containing acylhydrazones, hydrazines, diazenes, and related compounds were identified to disrupt the interaction between cellular LEDGF/p75 and HIV-1 IN. LEDGF/p75-IN inhibitor 7 had a central acylhydrazone and an $\mathrm{IC}_{50}$ of $400 \mathrm{nM}$. Allosteric IN inhibitors offer a promising approach in preventing viral replication by inhibiting the interaction between IN and LEDGF/p75. Two compounds identified from this study, $\mathbf{3 5}$ and
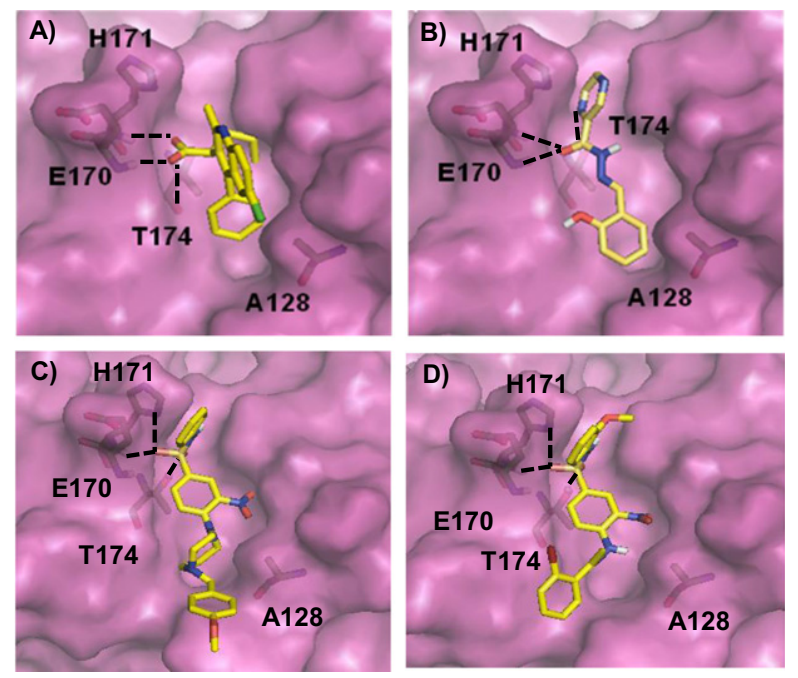

Figure 6. Molecular docking poses of LEDGF/p75-IN inhibitors in the LEDGF/p75 binding site at the IN dimer interface. All predicted interactions had distances within 3 angstroms and the potential ligand hydrogen bonds are provided in dashed lines. (A) LEDGF/p75-IN inhibitor 976 adopted from the 3LPU crystal structure. (B) Most active LEDGF/p75-IN inhibitor 7 identified in this study docked in close proximity for a stacking interaction with H171. (C) Antiviral LEDGF/p75-IN inhibitor 35. (D) LEDGF/p75-IN inhibitor 56.

56, showed antiviral activity warranting further investigation into hydrazines and their analogues as potential lead compounds for LEDGF/p75-IN inhibition. These compounds in general have low molecular weight and are amenable to further optimization while maintaining drug-like properties.

\section{Experimental section}

\subsection{Materials}

All compounds were purchased from Enamine Ltd as solid powder, freshly dissolved in DMSO, and stock solutions stored at $-20{ }^{\circ} \mathrm{C} . \quad \gamma-\left[{ }^{32} \mathrm{P}\right]-\mathrm{ATP}$ was purchased from American Radio- 
chemicals (ARC, Inc.). The expression system for the wild-type IN was a generous gift of Dr. Robert Craigie, Laboratory of Molecular Biology, NIDDK, NIH, Bethesda, MD.

\subsubsection{Recombinant protein expression and purification}

Protein expression plasmids pGEX-6P-3 and pET-15b-IN encoding the LEDGF/p75 fusion protein gene and HIV-1 IN gene respectively, were transformed into competent Escherichia coli pLysS BL21 (DE3) bacterial cells through heat shock and plated on $100 \mu \mathrm{g} / \mathrm{ml}$ ampicillin LB-agar plates. The plasmid pGEX-6P-3 encoded for a FLAG peptide gene, while pET-15b included a hexa-histidine tag on the IN C-terminus. The plasmids contain a T7 promoter region to promote the overexpression of transformed genes only and an ampicillin-resistant gene to positively select for correctly transformed colonies. Bacteria were grown in large bacterial culture vats at $37^{\circ} \mathrm{C}, 250 \mathrm{rpm}$, and protein expression was induced with $1 \mathrm{mM} \mathrm{IPTG}$. Bacteria were then centrifuged using a Beckman Coulter 6KR centrifuge for $20 \mathrm{~min}$ at $3000 \mathrm{rpm}$ and lysed using French Pressure Cell Press (ThermoSpectronic, Inc.). Recombinant LEDGF/p75 was isolated using a general non-tagged purification protocol using Heparin HP and Sepharose SP columns according to the manufacture (Thermoelectronic, Inc.). Recombinant IN was isolated using a nickel-chelating column and extracted using increasing imidazole concentrations at $4{ }^{\circ} \mathrm{C}$. Overnight dialysis at $4{ }^{\circ} \mathrm{C}$ concentrates purified proteins in $50 \mathrm{mM} \mathrm{NaCl}$, $1 \mathrm{mM}$ HEPES, pH 7.5, $50 \mu \mathrm{M}$ EDTA, $50 \mu \mathrm{M}$ DTT, 10\% glycerol buffer stock solutions, and purified protein solutions were stored at $-80^{\circ} \mathrm{C}$.

\subsubsection{Preparation of oligonucleotide substrates}

Oligonucleotides mimicking the LTR regions 5'-GTGTGGA AAATCTCTAGCAGT-3' and 5'-ACTGCTAGAGATTTTCCACAC-3' were purchased from Norris Cancer Center Core Facility (University of Southern California) and purified by UV shadowing on polyacrylamide gel. To analyze the extent of 3 -processing and strand transfer using $5^{\prime}$-end labeled substrates, the 21 -mer forward strand was radioactively labeled in the $5^{\prime}$-end end using a T4 polynucleotide kinase (Epicentre, Madison, WI) and $\gamma-\left[{ }^{32} \mathrm{P}\right]-A T P$ (ARC, Inc.). The kinase was heat-inactivated and the complementary reverse strand was added in 1.5 -molar excess. The mixture was heated at $95^{\circ} \mathrm{C}$, and then allowed to cool slowly to room temperature. The newly annealed oligonucleotide was purified through a spin 25 mini-column (USA Scientific) to separate annealed double-stranded oligonucleotide from unincorporated material.

\subsection{Biological assays}

\subsubsection{LEDGF/p75-IN AlphaScreen proximity luminescent assay}

The AlphaScreen assay was performed according to the manufacturer's protocol (Perkin Elmer, Waltham, MA). Reactions were performed in $25 \mu$ l final volume in 384-well Optiwell ${ }^{\mathrm{TM}}$ microtiter plates (Perkin Elmer). The reaction buffer contained $25 \mathrm{mM}$ Tris$\mathrm{HCl}$ ( $\mathrm{pH} 7.4$ ), $150 \mathrm{mM} \mathrm{NaCl}, 1 \mathrm{mM} \mathrm{MgCl} 2,0.01 \%$ (v/v) Tween-20 and $0.1 \%(\mathrm{w} / \mathrm{v})$ bovine serum albumin. Wild type IN with a $\mathrm{His}_{6}{ }^{-}$ tag (300 nM final concentration) was pre-incubated with each inhibitor for $30 \mathrm{~min}$ at $4{ }^{\circ} \mathrm{C}$. Next, $100 \mathrm{nM}$ Flag peptide taggedLEDGF/p75 was added to the reaction and incubated for an additional hour at $4{ }^{\circ} \mathrm{C}$. Subsequently $5 \mu \mathrm{l}$ of $\mathrm{Ni}$-chelate-coated donor beads and $5 \mu \mathrm{l}$ anti-Flag acceptor beads were added to a final concentration of $20 \mu \mathrm{g} / \mathrm{ml}$ for each beads. Proteins and beads were incubated for $1 \mathrm{~h}$ at $30^{\circ} \mathrm{C}$ in order to allow association to occur. Exposure of the reaction to direct light was omitted as much as possible and the emission of light from the acceptor beads was measured in the EnVision plate reader (Perkin Elmer).

\subsubsection{Counter screen}

A counter screen assay was conducted to observe compounds' ability to 'quench' the AlphaScreen bead signal and inhibit the non-specific interaction between the protein tags and their affinity to the beads. Some compounds absorb energy at the emission frequency significantly diminishing the output signal for accurate reading. As another example, molecules can theoretically interfere with the interaction of FLAG peptide with anti-FLAG acceptor bead, reporting as a false positive. An internal control substrate was provided by the company and was used to determine the nonspecific inhibition of compounds with the beads and tags as well as the disruption of emitting signal.

\subsubsection{Integrase enzymatic assay}

To determine the extent of $3^{\prime}$-processing and strand transfer, wild-type IN was pre-incubated at a final concentration of $200 \mathrm{nM}$ with the inhibitor in reaction buffer $(50 \mathrm{mM} \mathrm{NaCl}, 1 \mathrm{mM}$ HEPES, pH 7.5, $50 \mu \mathrm{M}$ EDTA, $50 \mu \mathrm{M}$ dithiothreitol, 10\% glycerol (w/v), $7.5 \mathrm{mM} \mathrm{MnCl}_{2}, 0.1 \mathrm{mg} / \mathrm{ml}$ bovine serum albumin, $10 \mathrm{mM}$ 2-mercaptoethanol, $10 \%$ dmso, and $25 \mathrm{mM}$ MOPS, $\mathrm{pH} 7.2$ ) at $30{ }^{\circ} \mathrm{C}$ for $30 \mathrm{~min}$. Then, $20 \mathrm{nM}$ of the $5^{\prime}$-end ${ }^{32} \mathrm{P}$-labeled linear oligonucleotide substrate was added, and the incubation was continued for an additional one hour. Reactions were then quenched by the addition of an equal volume $(16 \mu \mathrm{l})$ of loading dye (98\% deionized formamide, $10 \mathrm{mM}$ EDTA, 0.025\% xylene cyanol and 0.025\% bromophenol blue). An aliquot (5-10 $\mu \mathrm{l})$ was electrophoresed on denaturing $20 \%$ polyacrylamide gels $(0.09 \mathrm{M}$ tris-borate $\mathrm{pH} 8.3$, 2 mM EDTA, 20\% acrylamide, $8 \mathrm{M}$ urea).

Gels were dried, exposed in a PhosphorImager cassette, and analyzed using a Typhoon 8610 Variable Mode Imager (Amersham Biosciences) and quantitated using ImageQuant 5.2.

Percent inhibition (\%I) was calculated using equation :\% I

$$
=100 \times[1-(D-C) /(N-C)],
$$

where $C, N$, and $D$ are the fractions of 21-mer substrate converted to 19-mer ( 3 '-processing product) or strand transfer products for DNA alone, DNA plus IN, and IN plus drug, respectively. The $\mathrm{IC}_{50}$ values were determined by plotting the logarithm of drug concentration versus percent inhibition to obtain the concentration that produced $50 \%$ inhibition.

\subsubsection{Growth inhibition assay}

Growth inhibition was assessed using a 3-(4,5-dimethylthiazol2-yl)-2,5-diphenyltetrazolium bromide (MTT) assay as described earlier. ${ }^{38}$ Cells were seeded in 96 -well microtiter plates, allowed to attach $24 \mathrm{~h}$ prior to the addition of corresponding compounds to the culture medium. After $72 \mathrm{~h}$, cells were incubated with $0.3 \mathrm{mg} / \mathrm{ml}$ MTT (Amresco) for an additional $3 \mathrm{~h}$ at $37^{\circ} \mathrm{C}$. After removal of the supernatant, dimethyl sulfoxide (DMSO) was added to the wells and the absorbance was read at $570 \mathrm{~nm}$. All assays were performed in triplicate. Percentage of cell growth inhibition was expressed as: $(1-\mathrm{A} / \mathrm{C}) \times 100 \%(\mathrm{~A}$ and $\mathrm{C}$ were the absorbance values from experimental and control cells, respectively). Inhibitory concentration $50 \%\left(\mathrm{IC}_{50}\right)$ values were determined for each drug from a plot of log (drug concentration) versus percentage of cell growth inhibition. Standard deviations were calculated based on the $\mathrm{IC}_{50}$ values obtained from at least three independent experiments.

\subsubsection{Cells in virus strain}

MT- 4 cells were grown in a humidified atmosphere with $5 \% \mathrm{CO}_{2}$ at $37^{\circ} \mathrm{C}$ and maintained in RPMI 1640 medium supplemented with $10 \%$ heat-inactivated fetal calf serum, $2 \mathrm{mM}$ L-glutamine, $0.1 \%$ sodium bicarbonate, and $20 \mu \mathrm{g} / \mathrm{ml}$ of gentamycin. ${ }^{39}$ MT- 4 cells were 
infected with HIV strains in the presence of the compounds. The origin of HIV-1 ( $\left.\mathrm{III}_{\mathrm{B}}\right)$ has been described. ${ }^{40}$

\subsubsection{Drug susceptibility assays}

The inhibitory effect of antiviral drugs on the HIV-induced CPE in MT-4 cell culture was determined by the MTT-assay. The 50\% cell culture infective dose of the HIV strains was determined by titration of the virus stock using MT- 4 cells. For the drug susceptibility assays, MT-4 cells were infected with 100-300 50\% cell culture infective doses $\left(\mathrm{CCID}_{50}\right)$ of the HIV strains in the presence of fivefold serial dilutions of the antiviral drugs. The concentration of the compound achieving 50\% protection against the CPE of $\mathrm{HIV}$, which is defined as the $50 \%$ effective concentration $\left(\mathrm{IC}_{50}\right)$, was determined. The concentration of the compound killing 50\% of the MT- 4 cells, which is defined as the $50 \%$ cytotoxic concentration $\left(\mathrm{CC}_{50}\right)$, was determined as well.

\subsection{Molecular docking}

Docking calculations were performed using GOLD Suite software. ${ }^{37}$ For each compound, the best 10 scored poses were collected for analysis. The crystal structure of LEDGF/p75 IBD in complex with an HIV-1 IN CCD dimer, PDB 2B4J, was used for our modeling studies. An extensive molecular docking study was performed using the standard default settings with 200 genetic algorithm runs on each molecule. Ligand flexibility was included by using options such as flipping of ring corners, amides, pyramidal nitrogens, secondary and tertiary amines, and rotation of carboxylate groups, as well as torsion angle distribution and post-process rotatable bonds as the default settings. We used the default cutoff values of $3.0 \AA(\mathrm{dH}-\mathrm{X})$ for $\mathrm{H}$-bonds and $4.0 \AA$ for van der Waals interactions. Hydrophobic fitting points were calculated to facilitate the correct starting orientation of the compound for docking by placing the hydrophobic atoms in the corresponding areas of the active site. When the top three solutions attained RMSD values within $1.5 \AA$ the docking was terminated.

\section{Acknowledgements}

This work was financially supported by funds from an $\mathrm{NIH} /$ NIAID (R21 AI081610) grant. TWS was funded by the NIH F31 (AI082942-01) and CHRP (D08-USC-321) awards. We would like to thank Luis Arechiga and Pedro Dominguez for their technical assistance in purifying the cellular protein LEDGF/p75.

\section{Supplementary data}

Supplementary data associated with this article can be found, in the online version, at http://dx.doi.org/10.1016/j.bmc.2012.12.012.

\section{References and notes}

1. Llano, M.; Saenz, D. T.; Meehan, A.; Wongthida, P.; Peretz, M.; Walker, W. H.; Teo, W.; Poeschla, E. M. Science 2006, 314, 461.

2. Pulsinelli, G. A.; Temin, H. M. Proc. Natl. Acad. Sci. U.S.A. 1994, 91, 9490.

3. Abram, M. E.; Ferris, A. L.; Shao, W.; Alvord, W. G.; Hughes, S. H. J. Virol. 2010, $84,9864$.

4. Cooper, D. A.; Steigbigel, R. T.; Gatell, J. M.; Rockstroh, J. K.; Katlama, C.; Yeni, P.; Lazzarin, A.; Clotet, B.; Kumar, P. N.; Eron, J. E.; Schechter, M.; Markowitz, M.;
Loutfy, M. R.; Lennox, J. L.; Zhao, J.; Chen, J.; Ryan, D. M.; Rhodes, R. R.; Killar, J. A.; Gilde, L. R.; Strohmaier, K. M.; Meibohm, A. R.; Miller, M. D.; Hazuda, D. J.; Nessly, M. L.; DiNubile, M. J.; Isaacs, R. D.; Teppler, H.; Nguyen, B. Y. N. Engl. J. Med. 2008, 359, 355.

5. Smith, R. J.; Okano, J. T.; Kahn, J. S.; Bodine, E. N.; Blower, S. Science 2010, 327, 697.

6. Ciuffi, A.; Llano, M.; Poeschla, E.; Hoffmann, C.; Leipzig, J.; Shinn, P.; Ecker, J. R.; Bushman, F. Nat. Med. 2005, 11, 1287.

7. Tsutsui, K. M.; Sano, K.; Hosoya, O.; Miyamoto, T.; Tsutsui, K. Nucl. Acids Res. 2011, 39, 5067.

8. Busschots, K.; Voet, A.; De Maeyer, M.; Rain, J. C.; Emiliani, S.; Benarous, R.; Desender, L.; Debyser, Z.; Christ, F. J. Mol. Biol. 2007, 365, 1480.

9. Rahman, S.; Lu, R.; Vandegraaff, N.; Cherepanov, P.; Engelman, A. Virology 2007, 357, 79.

10. Cherepanov, P.; Ambrosio, A. L.; Rahman, S.; Ellenberger, T.; Engelman, A. Proc. Natl. Acad. Sci. U.S.A. 2005, 102, 17308.

11. Hare, S.; Shun, M. C.; Gupta, S. S.; Valkov, E.; Engelman, A.; Cherepanov, P. PLoS Pathog. 2009, 5, e1000259.

12. Vandekerckhove, L.; Christ, F.; Van Maele, B.; De Rijck, J.; Gijsbers, R.; Van den Haute, C.; Witvrouw, M.; Debyser, Z. J. Virol. 2006, 2006, 80.

13. Engelman, A.; Cherepanov, P. PLoS Pathog. 2008, 4, e1000046.

14. Schrijvers, R.; De Rijck, J.; Demeulemeester, J.; Adachi, N.; Vets, S.; Ronen, K.; Christ, F.; Bushman, F. D.; Debyser, Z.; Gijsbers, R. PLoS Pathog. 2012, 8, e1002558.

15. De Luca, L.; Barreca, M. L.; Ferro, S.; Christ, F.; Iraci, N.; Gitto, R.; Monforte, A. M.; Debyser, Z.; Chimirri, A. ChemMedChem 2009, 4, 1311.

16. De Luca, L.; Ferro, S.; Gitto, R.; Barreca, M. L.; Agnello, S.; Christ, F.; Debyser, Z.; Chimirri, A. Bioorg. Med. Chem. 2010, 18, 7515.

17. Christ, F.; Shaw, S.; Demeulemeester, J.; Desimmie, B. A.; Marchand, A.; Butler, S.; Smets, W.; Chaltin, P.; Westby, M.; Debyser, Z.; Pickford, C. Antimicrob. Agents Chemother. 2012, 56, 4365.

18. Kessl, J. J.; Jena, N.; Koh, Y.; Taskent-Sezgin, H.; Slaughter, A.; Feng, L.; de Silva, S.; Wu, L.; Le Grice, S. F.; Engelman, A.; Fuchs, J. R.; Kvaratskhelia, M. J. Biol. Chem. 2012, 287, 16801.

19. Fan, X.; Zhang, F. H.; Al-Safi, R. I.; Zeng, L. F.; Shabaik, Y.; Debnath, B.; Sanchez, T. W.; Odde, S.; Neamati, N.; Long, Y. Q. Bioorg. Med. Chem. 2011, 19, 4935.

20. Rhodes, D. I.; Peat, T. S.; Vandegraaff, N.; Jeevarajah, D.; Newman, J.; Martyn, J.; Coates, J. A.; Ede, N. J.; Rea, P.; Deadman, J. J. ChemBioChem 2011, 12, 2311.

21. Christ, F.; Voet, A.; Marchand, A.; Nicolet, S.; Desimmie, B. A.; Marchand, D.; Bardiot, D.; Van der Veken, N. J.; Van Remoortel, B.; Strelkov, S. V.; De Maeyer, M.; Chaltin, P.; Debyser, Z. Nat. Chem. Biol. 2010, 6, 442.

22. Dayam, R.; Sanchez, T.; Clement, O.; Shoemaker, R.; Sei, S.; Neamati, N. J. Med. Chem. 2005, 48, 111.

23. Hare, S.; Gupta, S. S.; Valkov, E.; Engelman, A.; Cherepanov, P. Nature 2010, 464, 232.

24. Peat, T. S.; Rhodes, D. I.; Vandegraaff, N.; Le, G.; Smith, J. A.; Clark, L. J.; Jones, E. D.; Coates, J. A.; Thienthong, N.; Newman, J.; Dolezal, O.; Mulder, R.; Ryan, J. H.; Savage, G. P.; Francis, C. L.; Deadman, J. J. PLoS ONE 2012, 7, e40147.

25. Maartens, G.; Wilkinson, R. J. Lancet 2007, 370, 2030.

26. Park, W. B.; Kim, W.; Lee, K. L.; Yim, J. J.; Kim, M.; Jung, Y. J.; Kim, N. J.; Kim, D. H.; Kim, Y. J.; Yoon, J. H.; Oh, M. D.; Lee, H. S. J. Infect. 2010, 61, 323.

27. Preziosi, P. Curr. Drug Metab. 2007, 8, 839.

28. Tafazoli, S.; Mashregi, M.; O'Brien, P. J. Toxicol. Appl. Pharmacol. 2008, 229, 94.

29. Tian, B.; He, M.; Tang, S.; Hewlett, I.; Tan, Z.; Li, J.; Jin, Y.; Yang, M. Bioorg. Med. Chem. Lett. 2009, 19, 2162.

30. Arion, D.; Sluis-Cremer, N.; Min, K. L.; Abram, M. E.; Fletcher, R. S.; Parniak, M. A. J. Biol. Chem. 2002, 277, 1370.

31. Sluis-Cremer, N.; Arion, D.; Parniak, M. A. Mol. Pharmacol. 2002, 62, 398.

32. Al-Mawsawi, L. Q.; Christ, F.; Dayam, R.; Debyser, Z.; Neamati, N. FEBS Lett. 2008, 582, 1425.

33. Peloquin, C. A.; James, G. T.; Craig, L. D.; Kim, M.; McCarthy, E. A.; Ikle, D.; Iseman, M. D. Pharmacotherapy 1994, 14, 415.

34. Wang, H.; Jurado, K. A.; Wu, X.; Shun, M. C.; Li, X.; Ferris, A. L.; Smith, S. J.; Patel, P. A.; Fuchs, J. R.; Cherepanov, P.; Kvaratskhelia, M.; Hughes, S. H.; Engelman, A. Nucl. Acids Res. 2012, 40, 11518.

35. Ganapathy, V.; Daniels, T.; Casiano, C. A. Autoimmun. Rev. 2003, 2, 290

36. Basu, A.; Rojas, H.; Banerjee, H.; Cabrera, I. B.; Perez, K. Y.; De Leon, M.; Casiano, C. A. PLOS ONE 2012, 7, e30132.

37. Jones, G.; Willett, P.; Glen, R. C.; Leach, A. R.; Taylor, R. J. Mol. Biol. 1997, 267, 727.

38. Plasencia, C.; Grande, F.; Oshima, T.; Cao, X.; Yamada, R.; Sanchez, T.; Aiello, F.; Garofalo, A.; Neamati, N. Cancer Biol. Ther. 2009, 8, 458.

39. Miyoshi, I.; Taguchi, H.; Kobonishi, L.; Yoshimoto, S.; Ohtsuki, Y.; Shiaishi, Y. Gann Monogr. Cancer Res. 1982, 73, 339.

40. Popovic, M.; Sarngadharan, M. G.; Read, E.; Gallo, R. C. Science 1984, 224, 497. 